Table 2. Changes in RA parameters in patients treated with tofacitinib, $\mathrm{n}=374(\mathrm{M} \pm \mathrm{SE})$.

\begin{tabular}{lcccc}
\hline Disease characteristics & Baseline & Year $1^{\#}$ & Year $2^{\#}$ & Year $3^{\#}$ \\
\hline C-RP, $\mathrm{mg} / \mathrm{L}$ & $30.1 \pm 35.0$ & $8.3 \pm 12.8$ & $7.6 \pm 10.7$ & $9.4 \pm 13.5$ \\
ESR, mm/h & $35.2 \pm 21.2$ & $22.7 \pm 17.2$ & $21.9 \pm 17.7$ & $22.3 \pm 17.3$ \\
NTJ from 28 & $11.2 \pm 6.5$ & $4.6 \pm 4.9$ & $4.8 \pm 5.0$ & $3.9 \pm 3.8$ \\
NTJ from 28 & $7.6 \pm 5.1$ & $2.4 \pm 3.2$ & $1.7 \pm 3.1$ & $1.4 \pm 2.8$ \\
\hline
\end{tabular}

*difference with baseline is significant with $p<0.000$. " - \pm 28 days

Conclusion: According to the real world data treatment with tofacitinib may provide good response rates in RA patients, refractory to the previous csDMARDs treatment in long-term perspective.

Acknowledgments : Pfizer

Disclosure of Interests: : Inna Gaydukova Grant/research support from: JSC BIOCAD, Speakers bureau: Pfizer, Novartis, AbbVie, JSC BIOCAD, Celgene, MSD, Sanofi, V Mazurov: None declared, Alexander Lila: None declared, Andrey Baranov Grant/research support from: Bayer, Galina Lukina Speakers bureau: Novartis, Pfizer, UCB, Abbvie, Biocad, MSD, Roche, Evgeniy Zhilyaev Speakers bureau: Novartis, UCB, Pfizer, Biocad, Abbvie, MSD, Roche, Ekaterina Koltsova: None declared, Evgeniya Shmidt Speakers bureau: MSD, Novartis, Pfizer, Oxana Fomina: None declared, Irina Bondareva: None declared, Olga Anoshenkova: None declared, Aleksey Vasilenko: None declared, Elizaveta Vasilenko: None declared, Natalya Yudina: None declared, Larisa Knyazeva: None declared, Vyacheslav Poncratov: None declared, Ekaterina Gaydukova: None declared, Evgeny Nasonov Speakers bureau: Lilly, AbbVie, Pfizer, Biocad, R-Pharm DOI: 10.1136/annrheumdis-2020-eular.4664

\section{SAT0142 MATCHING ADJUSTED INDIRECT COMPARISON OF FILGOTINIB VS. TOFACITINIB IN MODERATE- TO-SEVERE ACTIVE RHEUMATOID ARTHRITIS PATIENTS WITH INADEQUATE RESPONSE TO METHOTREXATE}

M. Gharaibeh ${ }^{1}$, N. Smith ${ }^{2}$, S. Jeyakumar ${ }^{2}$, E. Mark ${ }^{1}$, S. Shreay ${ }^{1} .{ }^{1}$ 1. Gilead Science Inc, Foster City, United States of America; ${ }^{2}$ Maple Health Group, LLC, New York, United States of America

Background: Filgotinib (FILG) is a JAK1 inhibitor that has been investigated in combination with methotrexate (MTX) for the treatment of moderate-to-severe rheumatoid arthritis (RA). To date, no head-to-head trial has compared the efficacy of FILG versus tofacitinib (TOFA).

Objectives: To compare the efficacy of FILG $200 \mathrm{mg}+$ MTX with TOFA $5 \mathrm{mg}$ + MTX using matching adjusted indirect comparison (MAIC).

Methods: MAIC technique uses individual patient data (IPD) from one trial and aggregate data from the other to enable comparison of outcomes after matching on baseline characteristics [1]. An anchored MAIC was conducted using IPD from the FINCH-1 trial of FILG $200 \mathrm{mg}+$ MTX vs adalimumab (ADA) $40 \mathrm{mg}+$ MTX and published data from ORAL STRATEGY [2] trial of TOFA $5 \mathrm{mg}+$ MTX vs ADA $40 \mathrm{mg}+\mathrm{MTX}$. Patients in the FINCH-1 trial were reweighted based on age, sex, race, tender joint count 28 , swollen joint count 28 , C-reactive protein and patient's global assessment to match baseline characteristics of the comparator. After matching, Wald tests were used to test for significant differences in ACR 20/50/70 and clinical remission outcomes (SDAI $\leq 3.3$, CDAI $\leq 2.8$, DAS28(CRP) $<2.6$, Boolean) between FILG + MTX vs TOFA $5 \mathrm{mg}+$ MTX relative to ADA $40 \mathrm{mg}+$ MTX.

Results: After matching, baseline characteristics were balanced across the trial populations [Table 1]. FILG $200 \mathrm{mg}+$ MTX patients experienced significantly greater improvement in 12 week ACR50 and ACR70 outcomes compared to TOFA $5 \mathrm{mg}+$ MTX with a mean difference in difference (DD) of $13.5 \%$ $(p<.05)$ and $8.3 \%(p<.05)$ respectively, as well as numerical improvements on other ACR outcomes at 12, 24 and 52 weeks [Figure 1]. At 24 weeks, FILG $200 \mathrm{mg}+$ MTX patients experienced significantly greater improvement in DAS28(CRP) clinical remission compared to TOFA $5 \mathrm{mg}+$ MTX with DD of $10.1 \%(p<.05)$ [Figure 2] as well as numerical improvements on other efficacy outcomes. At 52 weeks, FILG $200 \mathrm{mg}+$ MTX patients experienced significantly greater improvement in DAS28(CRP) clinical remission compared to TOFA $5 \mathrm{mg}+$ MTX with DD of $13.2 \%(\mathrm{p}<.05)$ [Figure 2] as well as numerical improvements on other efficacy outcomes.
Table 1. Baseline Characteristics of FINCH-1 vs ORAL STRATEGY

\begin{tabular}{|c|c|c|c|c|c|c|}
\hline \multirow[t]{2}{*}{ CHARACTERISTIC } & \multicolumn{4}{|c|}{ BEFORE MATCHING AFTER MATCHING } & \multicolumn{2}{|c|}{ ORAL STRATEGY } \\
\hline & $\begin{array}{c}\text { FILG } 200 \\
+ \text { MTX } \\
(\mathrm{N}=475)\end{array}$ & $\begin{array}{c}\text { ADA } \\
+\mathrm{MTX} \\
(\mathrm{N}=325)\end{array}$ & $\begin{array}{c}\text { FILG } 200 \\
+ \text { MTX } \\
(E S S=340)\end{array}$ & $\begin{array}{c}\text { ADA } \\
+ \text { MTX } \\
(E S S=233)\end{array}$ & $\begin{array}{l}\text { TOFA 5mg } \\
+ \text { MTX BID } \\
(\mathrm{N}=376)\end{array}$ & $\begin{array}{c}\text { ADA + } \\
\text { MTX BID } \\
(\mathrm{N}=386)\end{array}$ \\
\hline Sex - Female, \% & $79.8 \%$ & $81.8 \%$ & $83.0 \%$ & $83.0 \%$ & $83.0 \%$ & $83.0 \%$ \\
\hline Race - White, \% & $65.7 \%$ & $70.5 \%$ & $76.0 \%$ & $76.0 \%$ & $76.0 \%$ & $76.0 \%$ \\
\hline $\begin{array}{l}\text { Tender Joint Count } \\
\text { 28, mean (SD) }\end{array}$ & $15.0(6.4)$ & $14.6(6.3)$ & $15.6(6.5)$ & $15.2(6.7)$ & $15.6(6.5)$ & $15.2(6.7)$ \\
\hline $\begin{array}{l}\text { Swollen Joint Count } \\
28 \text {, mean (SD) }\end{array}$ & $11.2(5.2)$ & $11.2(5.0)$ & $11.8(5.7)$ & $11.0(5.4)$ & $11.8(5.7)$ & $11.0(5.4)$ \\
\hline $\begin{array}{l}\text { C-Reactive Protein } \\
\text { (mg/L), mean (SD) }\end{array}$ & $16.1(21.0)$ & $14.6(18.0)$ & ) $18.7(21.9)$ & 16.7 & $18.7(21.9)$ & ) $16.7(21.3)$ \\
\hline $\begin{array}{l}\text { Patient global assess- } \\
\text { ment baseline, mean } \\
\text { (SD) }\end{array}$ & $-67.1(19.2)$ & $67.0(19.1)$ & $61.7(22.0)$ & $60.2(23.5)$ & 61.7 & $60.2(23.5)$ \\
\hline
\end{tabular}

ESS = effective sample size; $\mathrm{SD}=$ standard deviation

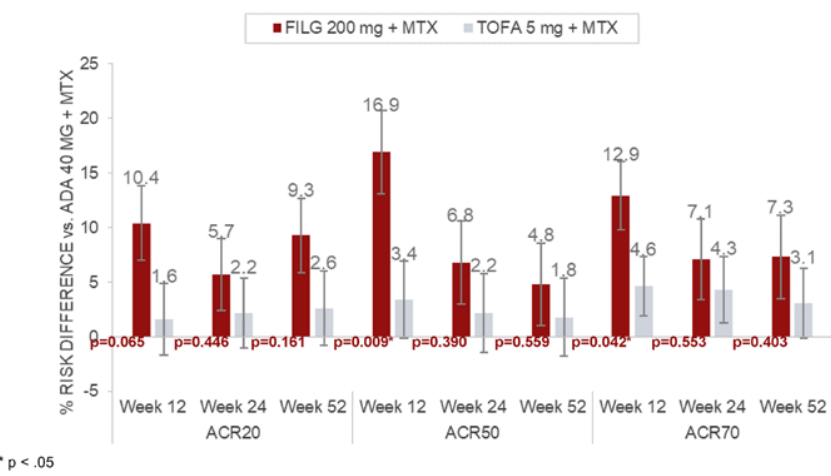

Figure 1. ACR20/50/70 relative to ADA $40 \mathrm{mg}+$ MTX of FILG $200 \mathrm{mg}+$ MTX vs TOFA $5 \mathrm{mg}+$ $\mathrm{MTX}^{*} \mathrm{p}<.05$

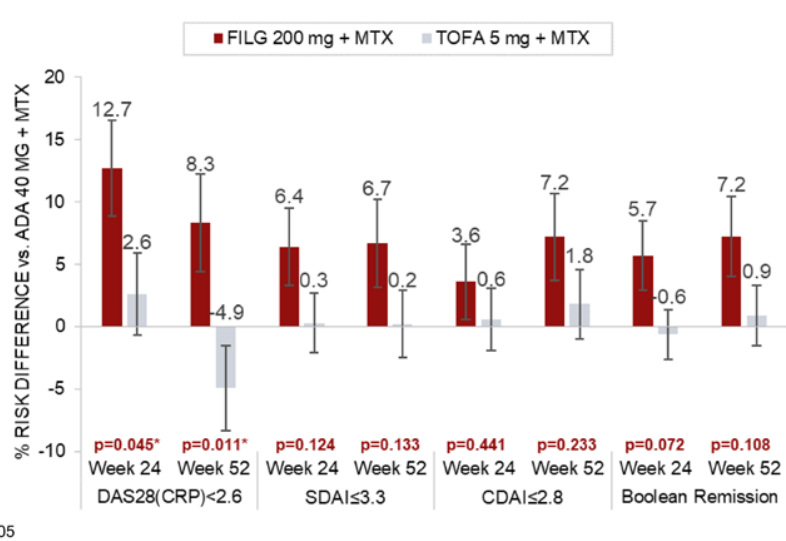

Figure 2. Clinical Remission outcomes relative to ADA $40 \mathrm{mg}+\mathrm{MTX}$ of FILG $200 \mathrm{mg}+$ MTX vs TOFA $5 \mathrm{mg}+$ MTX ${ }^{*} \mathrm{p}<.05$

Conclusion: In this MAIC, compared to TOFA 5mg + MTX, FILG $200 \mathrm{mg}+$ MTX appears to produce improved efficacy outcomes (ACR20/50/70, DAS28(CRP), SDAI, CDAI and Boolean Remission) at weeks 12, 24 and 52.

References:

[1] Signorovitch JE, et al. "Matching-adjusted indirect comparisons: a new tool for timely comparative effectiveness research." Value in Health 15.6 (2012): 940-947

[2] Fleischmann R, et al. "Efficacy and safety of tofacitinib monotherapy, tofacitinib with methotrexate, and adalimumab with methotrexate in patients with rheumatoid arthritis (ORAL Strategy)." The Lancet 390.10093 (2017): 457-468

Acknowledgments: The study was funded by Gilead Sciences Inc 
Disclosure of Interests: Mahdi Gharaibeh Shareholder of: Gilead Sciences Inc, Employee of: Gilead Sciences, Amgen, Nate Smith Consultant of: Gilead Sciences Inc, Sushanth Jeyakumar Consultant of: Gilead Sciences, Ejim Mark Shareholder of: Gilead Sciences Inc, Employee of: Gilead Sciences, Novartis, Sanatan Shreay Shareholder of: Gilead Sciences, Employee of: Gilead Sciences DOI: 10.1136/annrheumdis-2020-eular.6108

\section{SAT0143 A PHASE 1 STUDY IN HEALTHY VOLUNTEERS EXPLORING THE SAFETY, PHARMACOKINETICS AND PHARMACODYNAMICS OF ATI-450: A NOVEL ORAL MK2 INHIBITOR}

J. Schnyder ${ }^{1}$, J. Monahan ${ }^{1}$, W. Smith ${ }^{1}$, H. Hope ${ }^{1}$, D. Kelly ${ }^{1}$, D. Burt ${ }^{1}$, E. Huff ${ }^{1}$, A. Kaul ${ }^{1}$, A. Hildebrand ${ }^{1}$, B. Burnette ${ }^{1}$, N. Klug ${ }^{1}$, M. Bangs ${ }^{1}$, D. Gordon ${ }^{1} .{ }^{1}$ Aclaris Therapeutics, Inc, Wayne, United States of America

Background: ATI-450, is an investigational small molecule inhibitor of the MAPK-activated protein kinase 2 (MK2) signaling pathway. This pathway drives the expression of multiple cytokines including TNFa, IL-1a and $\beta$, and IL-6.

Objectives: We evaluated the safety and tolerability of ATI-450 in healthy volunteers as well as pharmacokinetics (PK) and pharmacodynamics (PD). Here we present data from single and multiple ascending dose cohorts. The aim was to select a dose for evaluation in phase 2 in patients with rheumatoid arthritis.

Methods: Safety, PK and PD were assessed in a randomized, observer-blind, placebo-controlled, phase 1 study in male and female healthy subjects aged 18-55 $(n=77)$

- Part A: Single Ascending Dose (SAD) ( $n=32,8$ subjects per dose cohort - 2 placebo, 6 active). A single dose of $10 \mathrm{mg}, 30 \mathrm{mg}, 50 \mathrm{mg}$ and $100 \mathrm{mg}$ was tested.

- Part B: Multiple Ascending Dose (MAD) ( $n=30,10$ subjects per dose cohort - 2 placebo, 8 active). 10mg BID, 30mg BID and 50mg BID doses were tested over 7 days of administration.

Safety and tolerability of ATI-450 was evaluated based on adverse events, clinical laboratory, vital signs, 12-lead ECG, Holter monitoring, and physical examination. Blood was drawn for PK analysis at 0.5, 1, 2, 4, 6, 8, 12 hours, 24, 36, and 48 hours post dose in the SAD cohort and on day 7 of the MAD cohort. PD of ATI-450 were explored by investigating the inhibition of a target biomarker, phospho-HSP27 (pHSP27) and proinflammatory cytokines, TNFa, IL1 $\beta$, IL6 and IL8 in ex-vivo LPS-stimulated blood samples collected 4 and 12 hours post dose on day 7 from subjects in the MAD cohorts.

Results: ATI-450 was generally well tolerated. No serious adverse events or severe adverse events were reported, and no adverse events led to discontinuation of the study medication. The most common adverse events (reported by 2 or more subjects who received ATI-450) observed during the trial were dizziness, headache, upper respiratory tract infection, constipation, nausea, and abdominal pain. All adverse events were mild. A trend of a decrease in absolute neutrophil count (ANC) was observed without correlated clinical sequelae.

ATI-450 had dose proportional PK with a terminal half-life ( $\left.t 1 \frac{1}{2}\right)$ of 9-12 hours in the MAD cohort on day 7. A dose and concentration dependent inhibition of ex vivo stimulated cytokines and target biomarker was observed. On day 7 , patients in the $50 \mathrm{mg}$ BID dose (the dose with the highest degree of inhibition) recorded mean trough drug levels (12 hours post dose) that were 1.4, 2.5, 2.5 and 2.4 times greater than the $\mathrm{IC}_{80}$ for TNFa, IL1 $\beta$, IL8 and pHSP27 respectively. Mean Cmax drug levels (4 hours post dose) were 3.6, 6.4, 6.2 and 6.0 times greater than the IC 8 for TNFa, IL1 $\beta$, IL8 and pHSP27 respectively. IL6 levels were inhibited by more than $50 \%$ for part of the dosing interval.

Conclusion: Oral ATI-450 was generally well tolerated at all doses with dose proportional PK. The $t \frac{1}{2}$ suggests that once or twice daily oral dosing may be possible. At the 50mg BID dose, marked inhibition of TNFa, IL1 $\beta$ and IL8, IL6 and pHSP27 was observed. ATI-450 has the potential to be an oral, small molecule drug which can target multiple cytokines. Exploration of its benefit to risk profile in patients with rheumatoid arthritis is warranted.

Disclosure of Interests: Judy Schnyder Shareholder of: aclaris therapeutics, Employee of: aclaris therapeutics, Joe Monahan Shareholder of: aclaris therapeutics, Employee of: aclaris therapeutics, Walter Smith Shareholder of: aclaris therapeutics, Employee of: aclaris therapeutics, Heidi Hope Shareholder of: aclaris therapeutics, Employee of: aclaris therapeutics, Deborah Kelly Shareholder of: aclaris therapeutics, Employee of: aclaris therapeutics, David Burt Shareholder of: aclaris therapeutics, Employee of: aclaris therapeutics, E Huff Shareholder of: aclaris therapeutics, Employee of: aclaris therapeutics, A Kaul Shareholder of: aclaris therapeutics, Employee of: aclaris therapeutics, A Hildebrand Shareholder of: aclaris therapeutics, Employee of: aclaris therapeutics, B Burnette Shareholder of: aclaris therapeutics, Employee of: aclaris therapeutics, N Klug Shareholder of: aclaris therapeutics, Employee of: aclaris therapeutics, M Bangs Shareholder of: Aclaris Therapeutics, Employee of: Aclaris Therapeutics, David Gordon Shareholder of: aclaris therapeutics, Employee of: aclaris therapeutics DOI: 10.1136/annrheumdis-2020-eular.5645

\section{SAT0144 DOES POLYPHARMACY IN RHEUMATOID ARTHRITIS} PATIENTS AFFECT THE TREAT TO TARGET STRATEGY?

J. F. Jaramillo Gallego ${ }^{1}$, J. Rosa ${ }^{1}$, M. Scolnik ${ }^{1}$, M. A. Tobar Jaramillo ${ }^{1}$,

L. Ferreyra ${ }^{1}$, E. Soriano ${ }^{1} .{ }^{1}$ Hospital Italiano de Buenos Aires, Buenos Aires, Argentina

Background: Polypharmacy (PP) is an important risk factor for drug toxicity, delirium, falls, hospitalizations and death. Patients with rheumatoid arthritis (RA) often have comorbid conditions and have PP. Treat to target strategy (T2T) implies a drug escalation and rheumatologists may not apply it in patients with PP.

Objectives: Our objective was to analyze if PP affects T2T in a real-world scenario. Methods: Observational, retrospective cohort study. Patients with a new RA diagnosis (ACR/EULAR 2010 criteria) after 2010, over 18 years old, belonging to a Health Management Organization (HMO) from a university tertiary hospital, with a minimum follow-up period of 2 years, were included. PP was defined as consumption greater than or equal to 5 medications at the time of RA diagnosis, regardless of the medication used for RA, administered for a minimum period of 6 months. T2T strategy was defined as accomplished if an escalation in treatment was done when the patient had moderate or high disease activity at medical visit (by DAS28 and/or CDAI), without a significant improvement with respect to the previous visit. Prevalence of PP at RA diagnosis was calculated and RA patients were divided in those with PP at RA diagnosis time and those without. The first 2 years of disease were analyzed and compare between both groups: clinical and demographic characteristics, percentage of visits where T2T was applied, treatments received during that period. A multivariate logistic regression analysis was performed in order to identify factors associated with no T2T compliance.

Results: 147 patients with RA were included, $86 \%$ women, with an average age at diagnosis of 60 years (SD: 15.8). The prevalence of PP at RA diagnosis was $12 \%$ (17 patients). Table 1 shows the comparison between patients with and without $\mathrm{PP}$ Patients with PP showed a greater frequency of erosions at baseline and after 2 years of disease, a greater use of corticosteroids at 2 years, higher percentage of hospitalizations and a higher mortality. In the multivariate logistic regression analysis, no compliance of the T2T strategy was only associated with the consumption of corticosteroids at 2 years (OR: $0.36, \mathrm{Cl} 95 \%$ : $0.15-0.85 ; p=0.019$ ) and no association was found with $\mathrm{PP}$ at the beginning of the disease.

Table 1. Demographic and clinical characteristics in patients with and without polypharmacy.

\begin{tabular}{lccc}
\hline & $\begin{array}{c}\text { Patients without } \\
\text { Polypharmacy } \\
(\mathbf{n = 1 2 7 )}\end{array}$ & $\begin{array}{c}\text { Patients with } \\
\text { Polypharmacy } \\
(\mathbf{n = 1 7 )}\end{array}$ & $\mathbf{P}$ \\
\hline Male sex, $\mathrm{n}(\%)$ & $18(13.8)$ & $3(17.6)$ & 0.6 \\
Mean age at diagnosis (SD) & $58.5(15.6)$ & $70.6(12.2)$ & 0.9 \\
Positive rheumatoid factor, $\mathrm{n}(\%)$ & $87(66.9)$ & $12(70.5)$ & 0.7 \\
Positive anti CCP, $\mathrm{n}(\%)$ & $109(85.8)$ & $13(81.2)$ & 0.6 \\
Erosions at baseline, $\mathrm{n}(\%)$ & $25(19.2)$ & $7(41.1)$ & 0.03 \\
Active smoker, $\mathrm{n}(\%)$ & $28(21.5)$ & $3(17.6)$ & 0.2 \\
Past smoker, $\mathrm{n}(\%)$ & $23(17.6)$ & $7(35.2)$ & \\
Charlson score, median (IQR) & $3(1-4)$ & $4(4-5)$ & $<\mathbf{0 . 0 0 0 1}$ \\
Polypharmacy at 2 years, $\mathrm{n}(\%)$ & $17(13.0)$ & $46.8(88.2)$ & $<0.0001$ \\
Rheumatological consultations in 2 years, & $8.6(3.3)$ & $8.8(3.1)$ & 0.6 \\
mean (DE), (IC 95\%) & $(8.0-9.2)$ & $(7.2-10.5)$ & \\
Corticosteroid therapy at 2 years, $\mathrm{n}(\%)$ & $29(22.3)$ & $8(47.0)$ & 0.02 \\
cDMARDs therapy at 2 years, $\mathrm{n}(\%)$ & $114(87.6)$ & $13(76.4)$ & 0.2 \\
Biologic therapy at 2 years, $\mathrm{n}(\%)$ & $13(10)$ & $4(23.5)$ & 0.1 \\
Erosions at 2 years, $\mathrm{n}(\%)$ & $29(22.3)$ & $9(52.9)$ & 0.007 \\
No T2T compliance, $\mathrm{n}(\%)$ & $65(50)$ & $5(29.4)$ & 0.1 \\
Hospitalizations, $\mathrm{n}(\%)$ & $12(9.2)$ & $7(41.1)$ & $<0.0001$ \\
Mortality, $\mathrm{n}(\%)$ & $2(1.5)$ & $2(11.7)$ & 0.01 \\
\hline
\end{tabular}

Conclusion: The prevalence of PP in our patients with a new RA diagnosis was $12 \%$ and was associated with more baseline erosions, a higher consumption of steroids, and a higher frequency of hospitalizations and mortality during the first 2 years of the disease. No relationship between PP and adherence to the T2T strategy was demonstrated. In the multivariate logistic regression analysis, no compliance with the T2T strategy was only associated to the consumption of corticosteroids at 2 years, may be reflecting a poorer disease control.

Disclosure of Interests: JOHN FREDY JARAMILLO GALLEGO: None declared Javier Rosa: None declared, Marina Scolnik: None declared, Mayra Alejandra Tobar Jaramillo: None declared, LEANDRO FERREYRA: None declared, Enrique Soriano Grant/research support from: AbbVie, Eli Lilly, GlaxoSmithKline, Novartis, Pfizer Inc, Sandoz, Consultant of: AbbVie, Eli Lilly, GlaxoSmithKline, Novartis, Pfizer Inc, Sandoz, Speakers bureau: AbbVie, Amber, Bristol-Myers Squibb, Eli Lilly, Novartis, Pfizer Inc, Roche

DOI: 10.1136/annrheumdis-2020-eular.5087 